\title{
Progress and limits of TSE diagnostic tools
}

\author{
Jacques GRASSI*, Séverine MAILlET, Stéphanie SiMON, Nathalie MoREL
}

CEA, iBiTecS, Service de Pharmacologie et d'Immunoanalyse, bâtiment 136, CEA/Saclay, 91191

Gif-sur-Yvette, France

(Received 2 October 2007; accepted 5 February 2008)

\begin{abstract}
Following the two "mad cow" crises of 1996 and 2000, there was an urgent need for rapid and sensitive diagnostic methods to identify animals infected with the bovine spongiform encephalopathy (BSE) agent. This stimulated research in the field of prion diagnosis and led to the establishment of numerous so-called "rapid tests" which have been in use in Europe since 2001 for monitoring at-risk populations (rendering plants) and animals slaughtered for human consumption (slaughterhouse). These rapid tests have played a critical role in the management of the mad cow crisis by allowing the removal of prion infected carcasses from the human food chain, and by allowing a precise epidemiological monitoring of the BSE epizootic. They are all based on the detection of the abnormal form of the prion protein $\left(\mathrm{PrP}^{\mathrm{Sc}}\right.$ or $\left.\mathrm{PrP}^{\mathrm{res}}\right)$ in brain tissues and consequently are only suitable for post-mortem diagnosis. Since it is now very clear that variant Creutzfeldt-Jakob disease (vCJD) can be transmitted by blood transfusion, the development of a blood test for the diagnosis of vCJD is a top priority. Although significant progress has been made in this direction, including the development of the protein misfolding cyclic amplification (PMCA) technology, at the time this paper was written, this objective had not yet been achieved. This is the most important challenge for the years to come in this field of prion research.
\end{abstract}

TSE diagnosis / PrP / blood test / PMCA

Table of contents

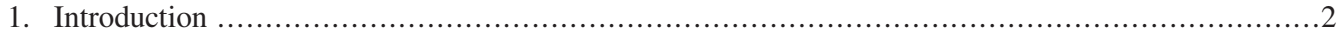

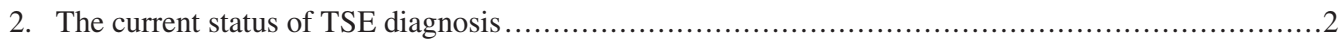

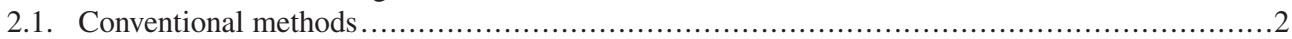

2.1.1. Histological and immunohistological techniques ......................................

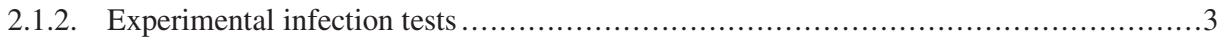

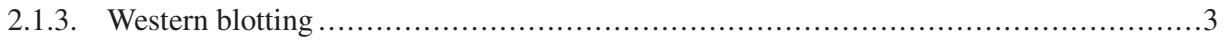

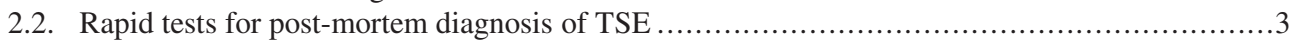

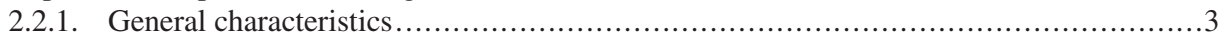

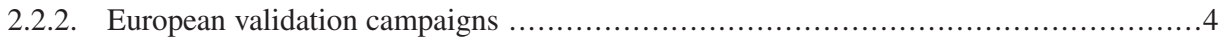

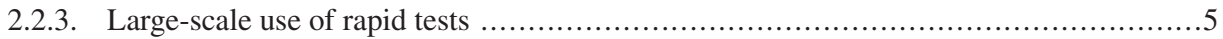

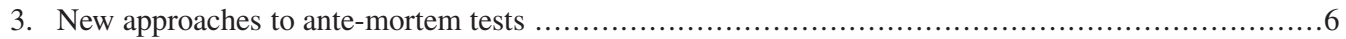

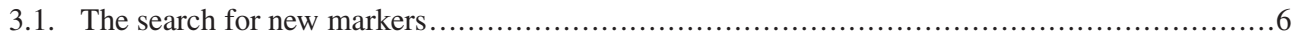

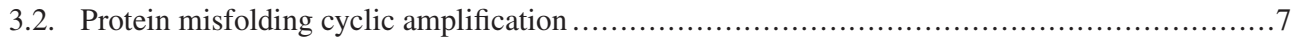

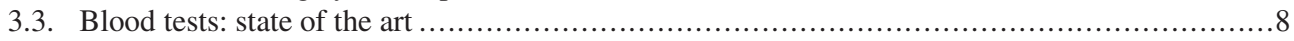

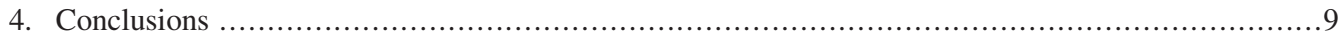

* Corresponding author: jacques.grassi@cea.fr 


\section{INTRODUCTION}

Humans have a long history of contact with animals affected by a transmissible spongiform encephalopathy (TSE), without apparent problems. Scrapie in sheep has been described since the 18th century and the available epidemiological data do not indicate a detectable risk for humans under natural conditions. The huge epizootic of bovine spongiform encephalopathy (BSE) in Great Britain that was first detected in 1986 (over 200000 confirmed cases to date) and, above all, the announcement in 1996 of possible transmission of BSE to humans in the form of the variant Creutzfeldt-Jakob disease (vCJD), created enormous concern among European consumers and triggered the first European-wide mad cow crisis. In 1999, testing of at-risk populations was introduced in some European countries and subsequently identified cases of BSE in countries previously believed to be untouched by the epizootic (Germany, Italy, Spain). This realisation triggered a further mad cow crisis at the end of 2000 and prompted the European authorities to take a whole series of measures to stop the spread of the epizootic, and to protect consumers from possible contamination by BSE. In particular, there was a total ban on meat and bone meal (held to be the main reason for BSE propagation in cattle) in livestock feed. Consumer protection was essentially ensured by removal of organs most likely to contain prions (specified risk material), and the implementation of systematic testing of all cattle aged between 24 and 30 months, depending on the carcass category and country ${ }^{1}$. The BSE epizootic has clearly receded since 2001 in Western Europe, but the situation is less clear in Eastern Europe.

Although arguments have accumulated since 1996 to confirm a link between BSE and vCJD [10, 11], fewer people are affected by vCJD than might have been feared (201 as

\footnotetext{
${ }^{1}$ This does not hold for the United Kingdom since, between 1996 and 2005, cattle over 30 months were not eligible for human consumption (certainly the more efficient protection), and consequently not systematically tested. The same active surveillance scheme as in other European countries has been in place since November 2005.
}

of August 2007, with 163 in the UK and 22 in France) all of them carrying the Met/Met genotype at codon 129 of the prion protein $(\mathrm{PrP})$. It is possible, however, that affected carriers of other genotypes (Val/Val and Met/Val) may appear in the future. Furthermore, a risk of secondary transmission within the human species is now clearly identified, following the detection in Great Britain of four cases linked to blood transfusion $[41,56,84]$.

In the late 1990s, there was a pressing need for rapid and sensitive diagnostic methods to identify animals infected by the BSE agent in order to define the extent of the epizootic and avoid transmission to humans. Surprisingly successful rapid tests have been developed since the mid-1990s and, as we shall see, have proven to be very useful.

The development of a blood test for the diagnosis of vCJD is now a priority, first to make blood transfusions safe, and secondly to identify affected individuals early so that treatment (which at present does not exist) can be initiated before neuroinvasion and onset of the first clinical signs. At the time this paper was written, this objective had not yet been achieved.

\section{THE CURRENT STATUS OF TSE DIAGNOSIS}

Before the mad cow epizootic, the diagnosis of prion diseases was not a public health or economic issue. For humans and live animals, it was essentially based on the analysis of clinical signs and post-mortem histological analysis.

\subsection{Conventional methods}

Historically, techniques used to diagnose TSE were designed to detect, in appropriate tissue samples, lesions characteristic of TSE, or disease associated forms of the prion protein $\left(\mathrm{PrP}^{\mathrm{Sc}}\right)$, or the transmissible agent itself.

\subsubsection{Histological and immunohistological techniques}

Histological detection of lesions typical of TSE (spongiosis, astrogliosis, amyloid plaques), essentially in the tissue of the central nervous system, is the reference method 
for confirming a clinical diagnosis [23]. It is very specific, since it allows direct observation of the signs of the disease, notably symmetrical spongiform lesions, but is less sensitive than other techniques [24, 83]. The sensitivity of microscopic observation can be increased by immunohistochemical techniques that use antibodies specific to PrP to detect accumulation of $\mathrm{PrP}^{\mathrm{Sc}}$ in amyloid deposits $[79,80]$. This technique's efficiency depends greatly on sample preparation and on the nature of the antibodies used. Although these methods are ill-suited to rapid, routine analysis, they are excellent for confirmation. They are also effective for the analysis of samples of lymphoid tissues (tonsils, Peyer's patches, lymph nodes) and can be utilised, for example, in preclinical diagnosis of scrapie in sheep [2,79] and chronic wasting disease [73], i.e., diseases characterised by marked replication of the prion in the lymphoid organs during the presymptomatic phase. The same observation has been reported for the diagnosis of vCJD and retrospective examination of over 8000 tonsil and appendix samples by immuno-histochemistry (IHC) identified one case of vCJD in Great Britain in a person presenting no clinical signs $[32,33]$.

\subsubsection{Experimental infection tests}

The most sensitive and specific method of diagnosing TSE is unquestionably experimental infection in laboratory animals. The animal is injected (usually by the intracranial route) with a homogenate prepared from the potentially infected tissue and is watched for the appearance of clinical signs. After the death of the experimentally infected animal, disease development is confirmed using classic techniques (histology, immunohistology, Western blot). For obvious practical reasons, these experiments are generally performed in rodents (mice, hamsters, bank voles). Recently, the availability of transgenic mice that overexpress the same PrP as that of the donor species has significantly increased the efficiency of experimental transmission and shortened incubation periods [71]. However, these methods are too labour-intensive and time-consuming for use in routine high-throughput screening.

\subsubsection{Western blotting}

Western blotting has been used to detect $\mathrm{PrP}^{\mathrm{Sc}}$ in tissue extracts for 20 years now [6]. Since all samples also always contain $\operatorname{PrP}^{\mathrm{C}}$, the protease-sensitive prion protein, they are systematically treated with proteinase K. After denaturation of the tissue extract by heating with sodium dodecyl sulfate (SDS), it is analysed by polyacrylamide gel electrophoresis (PAGE) and the denatured protein is transferred to a solid support and detected with an enzyme-labelled antibody. The specificity of Western blotting stems, among other things, from the fact that proteolysis with proteinase $\mathrm{K}$ characteristically alters the molecular weight of the PrPres, because of the partial degradation of the N-terminal part of the protein. As a consequence, in addition to the residual signal observed, the gel bands shift in a manner typical of $\mathrm{PrP}^{\mathrm{res}}$. This technique has enabled highly sensitive detection of $\mathrm{PrP}^{\mathrm{Sc}}$ in various tissues from vCJD patients [81]. Western blotting is also commonly used to characterise prion strains. The characteristics of the molecular pattern (size and relative intensity of the bands) of the three glycoforms of $\mathrm{PrP}^{\text {res }}$, and the reaction of certain antibodies directed against the N-terminal part of the PrP can, in some cases, be used to identify the molecular signature of the prion strain $[75,76]$.

\subsection{Rapid tests for post-mortem diagnosis of TSE}

\subsubsection{General characteristics}

None of the methods mentioned above are really suited to high-throughput screening, and cannot be automated. After the 1996 mad cow crisis, and the fear of possible transmission to humans, it became clear that there was a need to develop new simpler and faster diagnostic tests for large-scale epidemiological studies, and more accurate assessment of the characteristics of the epizootic, or for routine testing to warrant safety of animal meat, for instance, of all cattle before they enter the food chain or industrial circuits. A new generation of so-called "rapid" diagnostic tests emerged, all based on the immunological detection of $\mathrm{PrP}^{\mathrm{Sc}}$, the only identified reliable marker of TSE. 
It has long been perfectly apparent that antibodies can distinguish between the different conformations of the same protein, and the abnormal form of the prion protein is known to differ from the normal cellular form by its conformation, which contains a much higher proportion of $\beta$ sheets, and less $\alpha$ helices [57, 58]. Yet, despite several promising publications [17, 37, 54, 87], there are, as yet, no clearly identified antibodies that, under practical conditions, specifically recognise $\mathrm{PrP}^{\mathrm{Sc}}$ with satisfactory affinity in its native form. This is not the least of the paradoxes encountered in this field of research, but is beyond the scope of the present review.

In the absence of antibodies that specifically recognise $\mathrm{PrP}^{\mathrm{Sc}}$, it was necessary to resort to indirect approaches to distinguish between $\mathrm{PrP}^{\mathrm{Sc}}$ and $\mathrm{PrP}^{\mathrm{C}}$ in tissue extracts, which is generally present at a higher concentration. In almost all the rapid tests developed hitherto, this distinction is based on the distinct biochemical properties of the two forms of the protein. Most tests utilise the relative resistance of $\mathrm{PrP}^{\mathrm{Sc}}$ to degradation by proteolytic enzymes, particularly proteinase K. Other tests are based on the aggregation properties of $\mathrm{PrP}^{\mathrm{Sc}}$ when extracted using detergents. Note that the extraction of $\operatorname{PrP}\left(\mathrm{PrP}^{\mathrm{C}}\right.$ or $\left.\mathrm{PrP}^{\mathrm{Sc}}\right)$ is an indispensable step in all tests, because it is hard to envisage detecting PrP without extracting it from its neighbouring membrane structures. This is generally achieved by treating a tissue homogenate with one or more detergents. Lastly, all the rapid tests include a step in which $\mathrm{PrP}^{\text {res }}$ is denatured, to permit its detection by antibodies that recognise $\operatorname{PrP}^{\mathrm{C}}$ or denatured $\operatorname{PrP}$ (whether from $\operatorname{PrP}^{\mathrm{C}}$ or $\operatorname{PrP}^{\mathrm{Sc}}$ ).

\subsubsection{European validation campaigns}

In May 1999, the Directorate General XXIV (Consumer Policy and Consumer Health Protection) of the European Commission validated, under very strict conditions (blind testing in a limited time overseen by a European Commission representative), three tests (from Enfer Technology Ltd (Newbridge, Ireland), Prionics (Zurich, Switzerland), and CEA (Saclay, France)) that were suitable for rapid industrial development.
The Prionics test uses an industrialised format of Western blotting that enables largescale analysis [49, 65], and was the first rapid test used in large-scale epidemiological studies, first in Switzerland and then in France [12].

A diagnostic test developed by the CEA since 1998 is another example of a rapid test based this time on a conventional immunoenzyme approach (enzyme-linked immunosorbent assay, ELISA). This test is now marketed by Bio-Rad (Hercules, CA, USA, TeSeE tests). In the first step of the test, $\operatorname{PrP}^{\text {res }}$ is selectively purified using proteinase $\mathrm{K}$, centrifugation, and denaturation. In the second step, the solubilised and denatured $\mathrm{PrP}^{\mathrm{res}}$ is measured by a two-site (so-called sandwich) immunoassay that uses two monoclonal antibodies [27].

Enfer Technology Ltd developed an ELISA [46] in which $\mathrm{PrP}^{\mathrm{Sc}}$ is directly immobilised on a solid support in the presence of proteinase $\mathrm{K}$, denatured, and then detected using a polyclonal antibody directed against a peptide sequence characteristic of PrP.

The evaluation of these three tests was performed on more than 1600 brain stem samples from uninfected animals (1 000 animals from New Zealand) and from animals at the clinical stage of the disease (300 animals from the UK). Brain homogenates were also diluted to test the analytical sensitivity of the tests [46]. A fourth test (from Wallac, Bucks, UK) gave unsatisfactory results and was subsequently reevaluated in a substantially different format in 2001. The Enfer Technology, Prionics, and CEA tests were found to have $100 \%$ sensitivity and specificity on the series studied. Later work demonstrated that the CEA test, and its industrial version developed by Bio-Rad, were as sensitive as intracerebral inoculation tests in conventional RIII mice [20, 27]. It was also shown that rapid tests can also detect the accumulation of $\mathrm{PrP}^{\mathrm{res}}$ in nerve tissue before the appearance of clinical signs [3, 26].

In 2002 and 2004, 15 new tests were evaluated by the Directorate General for Health and Consumer Protection by a similar 
procedure, albeit on fewer samples ${ }^{2}$. Nine of the tests were approved for the post-mortem diagnosis of BSE: Prionics-Check LIA and Prionics-Check Prio-Strip (both from Prionics), TSE Kit Version 2.0 (Enfer), CDI-5 (InPro, San Francisco, USA), Ceditect BSE (Cedi, Lelystad, The Netherlands), HerdChek BSE Test Kit (IDEXX, Westbrook, USA), Speed'it BSE (Institut Pourquier, Montpellier, France), Beta Prion BSE EIA (Roboscreen, Leipzig, Germany) and PrionScreen (Roche, Basel, Switzerland).

Most of these new validated tests work in an ELISA format except Prio-Strip (lateral flow technology). However, three are based on markedly different principles. InPro's CDI5 and Cedi's Ceditect BSE detect $\mathrm{PrP}^{\mathrm{Sc}}$ by taking advantage of the fact that its immunoreactivity increases upon denaturation due to the unmasking of cryptic epitopes [63, 64]. HerdChek BSE from IDEXX is unique in two aspects, in that it does not use proteinase $\mathrm{K}$ digestion, and uses an aggregate specific capture ligand on a dextran polymer (Seprion ligand technology, Microsens Biotechnologies, London, $\mathrm{UK}$ ) of $\mathrm{PrP}^{\mathrm{Sc}}$, which after denaturation is detected using an anti-PrP antibody.

Today, virtually all testing of cattle is done with the tests from Bio-Rad, Prionics, IDEXX, and Enfer. Some of these tests have also proved effective in diagnosing chronic wasting disease in wild ruminants [31].

From 2002 to 2004, five tests validated for the post-mortem diagnosis of BSE in cattle were provisionally approved for the post-mortem diagnosis of TSE in small ruminants $^{3}$ : TeSeE (Bio-Rad), TSE Kit (En-

\footnotetext{
${ }^{2}$ The evaluation of five rapid tests for the diagnosis of spongiform encephalopathy in bovines (2nd study), 27 March 2002, http://ec.europa.eu/ food/food/biosafety/bse/sci_advice_en.htm, and scientific report of the European Food Safety Authority on the evaluation of seven new rapid post mortem BSE tests, 16 November 2004, http://www.efsa.europa.eu/EFSA/efsa_locale-1178 620753812_1178620780462.htm [consulted January 2008].

${ }^{3}$ Scientific report of the European Food Safety Authority on the evaluation of rapid post mortem TSE tests intended for small ruminants, adopted on 17
}

fer), CDI-5 (InPro), Prionics-Check LIA and Prionics-Check Western (both Prionics). Between 2004 and 2005, the European Commission specifically assessed nine tests for application to small ruminants, and recommended eight of them: TeSeE and TeSeE sheep/goat (Bio-Rad), TSE post-mortem test (IDEXX), Prionics-Check Western SR and Prionics-Check LIA SR (both from Prionics), Enfer TSE test Version 2.0 (Enfer), CDI-5 (InPro), Institut Pourquier Scrapie ELISA test (Institut Pourquier). It should be noted, however, that only the first three of these effectively detect atypical scrapie (Nor98) in brain stem samples. In practice, almost all testing on small ruminants is now done with the Bio-Rad, Prionics, IDEXX, and Enfer tests.

Note too that all results recorded using the rapid tests are confirmed in national reference laboratories, essentially using histopathology, immunohistochemistry, and Western blotting.

\subsubsection{Large-scale use of rapid tests}

Between 1st of January 2001 and 31st of December 2006, nearly 60 million tests on cattle within the European Community (almost $90 \%$ at the slaughterhouse) detected over 4800 cases of BSE, approximately 1170 at the slaughterhouse and about 3700 in at-risk animals collected in rendering plants ${ }^{4}$. Over the same period, passive surveillance detected only 2361 cases of BSE.

Rapid tests have therefore contributed significantly to consumer protection, first by providing a basis for confidence in meat safety, and secondly, because they led to the withdrawal of over 1000 infected carcasses from human consumption. In addition to the increased safety they provide, these large-scale analyses have detected BSE in

May 2005, http://efsa.europa.eu/EFSA/efsa_locale1178620753812_1178620780483.htm [consulted on January 2008].

${ }^{4}$ Reports on the monitoring and testing for the presence of TSE in the EU, 2001-2006, http://ec.europa.eu/food/food/biosafety/bse/annual_ reps_en.htm, and monthly report of Member States on BSE and TSE, http://ec.europa.eu/ food/food/biosafety/bse/mthly_reps_en.htm [consulted on January 2008]. 
numerous European countries (Austria, Czech Republic, Finland, Germany, Greece, Holland, Italy, Luxembourg, Poland, Slovakia, Slovenia, Spain), as well as in Japan, Canada, and the USA. They have also shown that many countries with no recorded case up to 2000 (e.g. Germany, Italy, and Spain), and which denied the presence of BSE, had an incidence equivalent to or higher than that of France and Switzerland, which have been recording cases since the early 1990s. Lastly, rapid tests allow much more precise epidemiological follow-up, allowing the measurement of trends at low prevalence, and which has more clearly shown a spectacular decline in the BSE epizootic in Europe.

Active monitoring of TSE in small ruminants (sheep and goats) was set up in Europe in March 2002, essentially to gather epidemiological data, and obliges member states of the European Community to test a quota of animals slaughtered normally or from at-risk populations. Between 2002 and 2006, nearly three million tests were performed, which led to the detection of over 13000 cases of scrapie ${ }^{4}$. Note that this active surveillance resulted in the detection of a great many cases of so-called atypical scrapie among European livestock. This form of scrapie, which very likely corresponds to strain Nor98 [7] identified in 1998 in Norway, now accounts for over $50 \%$ of TSE cases in small ruminants in many countries (France, Germany, Portugal, UK, etc.). The $\mathrm{PrP}^{\mathrm{Sc}}$ associated with this strain is characterised by increased sensitivity to proteinase $\mathrm{K}$, which makes its detection more difficult and explains why numerous rapid tests perform poorly in diagnosis. In practice, the vast majority of cases of atypical scrapie were identified using the tests from Bio-Rad (TeSeE since 2002) and IDEXX (post-mortem test, since 2005).

In view of the diversity of TSE strains present in small ruminants, the European Commission set up biochemical typing in 2005, mainly designed to identify the BSE strain in small ruminant populations ${ }^{5}$. Testing,

\footnotetext{
${ }^{5}$ Commission Regulation (EC) No 36/2005 of 12 January 2005 amending Annexes III and X to Regulation (EC) No 999/2001 of the Euro-
}

performed exclusively in national reference laboratories, is based on Western blotting techniques $[74,76]$. It is worth noting that, to date, only a single case of BSE, in a goat, was observed in France [21] before the implementation of this new regulation.

\section{NEW APPROACHES TO ANTE-MORTEM TESTS}

As we have seen, diagnosis of prion diseases depends principally on the detection of the abnormal form of $\operatorname{PrP}\left(\mathrm{PrP}^{\mathrm{Sc}}\right.$ or $\left.\mathrm{PrP}^{\text {res }}\right)$. This approach has been very useful in reacting to the BSE epizootic and in setting up active surveillance for TSE in ruminants, but to date has not met all the requirements of the diagnosis of prion diseases. These tests are only applicable to tissues collected after the death of the animal and so cannot be used for early preclinical diagnosis. So far, no test can give a reliable diagnosis using a readily available sample from a living animal or person, such as blood or urine. The problem is particularly acute for blood transfusion, insofar as it is now well established that vCJD can be transmitted by blood. Considerable effort has been devoted to the search for alternative markers enabling earlier diagnosis of TSE (for a review see Parveen et al. [55]).

\subsection{The search for new markers}

The search for alternative markers has grown greatly in recent years, boosted by the development of postgenomic approaches, which can be used for large-scale parallel analysis of the transcriptome, proteome, and metabolome of tissues. Attention naturally first turned to neuronal markers, which include protein 14-3-3 [28, 78], neurone-specific enolase [1], the protein S100B [5, 29], glial acidic fibrillar protein [44, 50], Tau protein [51], and prionins [59]. However, none of these markers has proved usable as a basis for a sufficiently sensitive and specific test allowing early preclinical diagnosis.

pean Parliament and of the Council as regards epidemio-surveillance for transmissible spongiform encephalopathies in bovine, ovine and caprine animals: http://ec.europa.eu/food/food/biosafety/bse/ legisl_en.htm [consulted 11 January 2008]. 
Metabolic markers, such as fatty acidbinding proteins, interferon $\gamma$, prostaglandin E2, C-reactive protein, interleukin 6, cystatin $\mathrm{C}$, and corticosteroids, have also been studied, but with no more success (for a review see Parveen et al. [55]).

Transcriptomic studies have revealed potential markers [70, 85], but to date none has proved of practical use in the diagnosis of prion diseases. Erythroid differentiationrelated factor, for example, initially seemed highly promising (downregulation [43]), but its value was not confirmed in subsequent work [25].

Finally, some research groups have developed an approach based on serum analysis by Fourier transform infrared spectroscopy combined with data processing by the neural network method [13, 39, 40, 69, 77]. This approach has shown high $(>90 \%)$ sensitivity and specificity in cattle populations, but it remains to be seen whether it is usable under routine conditions, and can be used to make an early diagnosis of TSE.

\subsection{Protein misfolding cyclic amplification}

To facilitate preclinical detection of prions in peripheral tissues, notably blood, Claudio Soto's group developed an original approach in which the $\mathrm{PrP}^{\mathrm{Sc}}$ in a sample is amplified by means of protein misfolding cyclic amplification (PMCA) [62]. In this approach, which seeks to mimic pathological processes and is akin to the polymerase chain reaction used to amplify DNA (but without addition of exogenous polymerase enzyme), $\mathrm{PrP}^{\mathrm{Sc}}$ is incubated in the presence of excess $\operatorname{PrP}^{\mathrm{C}}$ to allow expansion of aggregates of $\mathrm{PrP}^{\mathrm{Sc}}$ which are then dispersed by sonication to generate smaller units and to encourage the formation of new aggregates. The quantity of $\mathrm{PrP}^{\mathrm{Sc}}$ formed depends on the number of expansion/sonication cycles performed. In early articles [62, 72], amplification was modest (10- to 50-fold), but optimisation and automation subsequently enabled amplifications of several million fold [61]. In most studies, amplification is achieved by using as a source of $\operatorname{PrP}^{\mathrm{C}}$, a brain extract from the same species as that which produced the $\mathrm{PrP}^{\mathrm{Sc}}$ to be amplified. Recent works
$[18,19]$ have shown that $\operatorname{PrP}^{S c}$ can be replicated in a more controlled "minimal" system in the presence of highly purified $\operatorname{PrP}^{\mathrm{C}}$ (the only identified contaminant being lipids) and polyanions (polyA RNA in these studies).

Although most of the work by Soto's group concerns a hamster model infected by strain $263 \mathrm{~K}$, significant amplification has been achieved with the $\mathrm{PrP}^{\mathrm{Sc}}$ produced by various mammalian species, including mice [47, 72], sheep, goats and cattle [72], cervids [38] and humans [36]. The $\mathrm{PrP}^{\mathrm{Sc}}$ newly formed by PMCA has all the properties of the original $\mathrm{PrP}^{\mathrm{Sc}}$, notably its infectious character [14, 82]. Lastly, early detection of $\operatorname{PrP}^{\mathrm{Sc}}$ in hamster blood fractions (buffy coats) was achieved at a sensitivity ranging between 0 and $89 \%$ and a specificity of $100 \%[15,60]$.

PMCA has great potential and is certainly the most promising approach from the viewpoint of developing a blood test. It is, though, hampered by various fundamental and technical difficulties. Given the requirements imposed by a blood test (see paragraph below), notably in terms of practicability, sensitivity, and specificity, several technical improvements are needed. For adaptation to routine analysis, there is a need for simplification, reduction of the duration, and better control. Moreover, the obligatory requirement for a concentrated source of $\operatorname{PrP}^{\mathrm{C}}$ (brain extract or purified $\mathrm{PrP}^{\mathrm{C}}$ ) of the same species as the target to be amplified constitutes an important practical handicap. This specific problem could be resolved by the use of recombinant PrP and accelerated procedures as recently shown [4], assuming the results obtained with the hamster model can be extended to other mammalian species. However, PMCA must also prove effective in terms of diagnosis (sensitivity and specificity close to $100 \%$ ) using blood sample series more representative than those obtained with the hamster model. Finally, recent results from Supattapone's group show that infectious $\mathrm{PrP}^{\mathrm{Sc}}$ can be generated de novo and stochastically by PMCA [18] in the absence of pre-existing prions, and this raises concerns about the specificity of this approach when used in routine conditions. 


\subsection{Blood tests: state of the art}

As we have emphasised several times in this review, the development of a blood test is the top priority in prion disease diagnosis, notably to ensure the safety of blood transfusion in humans. Numerous difficulties, however, have to be overcome, which explains why no test is yet operational. Whereas blood from vCJD infected patients is clearly infectious $[41,56$, 84 ], its concentration of infectious material is very likely much lower than that in the central nervous system, and its concentrations of $\mathrm{PrP}^{\mathrm{Sc}}$ are estimated to be in the range of $\mathrm{pg} / \mathrm{mL}$ $[8,9]$. Given the efficacy of disease transmission by the intravenous route, and the large volume (commonly $>400 \mathrm{~mL}$ ) of packed red blood cells transfused in humans, transmission can occur with very low levels of infectious material, and, as a consequence, candidate tests must have excellent analytical sensitivity. Also, blood is a complex tissue rich in cells and proteins, and little is known of the distribution of prions (and of $\mathrm{PrP}^{\mathrm{Sc}}$ ). Several studies indicate that the bulk of the infectious material is in the white blood cells, but the plasma is also clearly infectious [8, 9]. In a healthy individual, significant levels of $\operatorname{PrP}^{\mathrm{C}}$ are present in white blood cells, red blood cells, platelets, and plasma, probably at much higher concentrations than $\mathrm{PrP}^{\mathrm{Sc}}$. A candidate test must therefore also be very selective. Also, we know very little about the biochemical properties of the $\mathrm{PrP}^{\mathrm{Sc}}$ in the different blood fractions. Given its low concentration and its environment, it is not certain, for instance, that it can form aggregates resistant to proteinase $\mathrm{K}$, the treatment on which most current rapid tests are based.

In terms of the risk of vCJD infection by blood transfusion, because the incidence of the disease is assumed to be very low, a highly specific test is needed, or it could lead to more false-positive results than detection of real cases. Such a situation would be very difficult to manage ethically, given that vCJD is a fatal disease for which at present there is no treatment. There is clearly a great need for at least one very specific confirmation test, which does not exist today.
Due to the above mentioned difficulties it is not surprising that very few publications report on blood tests for TSE.

The first promising results were obtained, as early as 1996, by the group of MaryJo Schmerr, which combined capillary electrophoresis with a competitive immunoassay to detect a PK resistant C-terminal sequence of PrP in the blood of sheep infected with scrapie [66-68]. The technique was subsequently improved and applied to more relevant series of scrapie infected sheep [34, 35, 42, 86], but despite achieved improvement, the method appeared insufficiently robust for routine use [22].

In recent years, many research groups or companies have developed original strategies to try to overcome the intrinsic difficulties associated with the blood test. These include:

- The use of ligands for a specific capture of $\mathrm{PrP}^{\mathrm{Sc}}$ possibly present in blood fractions, which include the 15B3 antibody produced by Prionics $[37,48]$ and the Seprion resin of the Microsense company (already used in the IDEXX test for post-mortem diagnosis). In both cases, the idea is to concentrate abnormal PrP by immunoprecipitation, taking advantage of its polymerisation state (aggregate? polymers? oligomers?) to allow a more sensitive and more specific detection by ELISA or flow cytometry. Another approach developed by the bioMérieux company (Marcy l'Étoile, France) involves binding and aggregation of abnormal PrP in plasma by streptomycin [45], followed by a specific capture on calyx-Arenes "molecular basket" immobilised onto a solid phase, and final detection with an appropriate anti-PrP antibody.

- The development of immunoassays designed to detect polymerised PrP (ASELISA, for aggregate specific ELISA) and based on the use of the same monoclonal antibody for capture and detection [52]. The sensitivity of AS-ELISA was increased by combining signal amplification (fluorescence) and target amplification (prion amplification using a simplified PMCA like procedure). Using 
this approach (named Am-A-FACTT) the group of Man-Sun Sy succeeded in detecting prion aggregates in plasma from mice or deer infected with scrapie or CWD respectively [16]. A similar approach has been developed by the Korean company PeopleBio (Seoul, Korea, Multimer Detection System (MDS)) without amplification of signal and target but details remain unpublished.

- The use of fluorescence labelled palindromic PrP peptides to detect misfolded PrP (MPD for misfolded protein diagnostic). In this approach, when the labelled peptide is in contact with $\mathrm{PrP}^{\mathrm{Sc}}$, it undergoes a large coil to a $\beta$-sheet conformational change which largely modifies the fluorescence properties of the pyrene label [30]. This method allowed discrimination between TSE infected and uninfected animals, albeit on a rather small series of blood samples [53].

However, even if some of these approaches seem promising, for the moment none of these tests has fulfilled the very strict analytical and diagnostic requirements described above. With the passage of time (some of these approaches were initially described a few years ago) it becomes apparent that they are facing real difficulties in establishing routine and robust assays, and that much more time and development is needed to achieve the goal of an operational blood test for TSE.

\section{CONCLUSIONS}

The successive "mad cow" crises of 1996 and 2000 have clearly boosted very significantly research in the field of prion diseases, and more data have been accumulated during the last ten years than during the previous century. This has considerably improved our knowledge on prion biology, but also provided much more relevant tools including: transgenic mice $\left(\mathrm{PrP}^{0 / 0}\right.$ or over-expressing various forms of wild-type or mutated PrP), cellular models of TSE infection, a large series of well characterised monoclonal antibodies and, of course, much more relevant analytical methods and diagnostic tests. As far as diagnosis is concerned, very significant progress has been made in the post-mortem detection of $\mathrm{PrPSc}^{\mathrm{Sc}}$, with the development of reliable and very sensitive methods suitable for routine analysis (results available within less than three hours, more than 20000 tests performed every day throughout the world), having the capacity of diagnosing TSE before the onset of clinical signs. These tests have been used efficiently for managing the mad cow crisis, and are still very useful for monitoring the BSE epizootic as well as the various forms of TSE in small ruminants and cervids. The analytical sensitivity of these tests can now be considerably improved by coupling PMCA amplification with the appropriate detection techniques (ELISA, CDI, Western-blot), and this allows detection of minute amounts of $\mathrm{PrP}^{\mathrm{Sc}}$ in the brain or in peripheral lymphoid tissues. However, so far, there is no test that delivers an early and specific diagnosis of TSE in live animals or patients, i.e. a test which can be easily applied to a body fluid like blood or urine. This is particularly critical for ensuring the safety of blood transfusion in countries that have experienced a large BSE epizootic (UK and Western Europe). We have seen that PMCA has shown a good potential, in terms of sensitivity, for achieving such an aim but its use in routine conditions and its actual specificity are questionable. There is thus a place for another approach, and the development of a blood test for TSE diagnosis remains the most important challenge for the years coming in this field of prion research.

\section{REFERENCES}

[1] Aksamit A.J. Jr., Preissner C.M., Homburger H.A., Quantitation of 14-3-3 and neuron-specific enolase proteins in CSF in Creutzfeldt-Jakob disease, Neurology (2001) 57:728-730.

[2] Andréoletti O., Berthon P., Marc D., Sarradin P., Grosclaude J., van Keulen L., et al., Early accumulation of $\operatorname{PrP}(\mathrm{Sc})$ in gut-associated lymphoid and nervous tissues of susceptible sheep from a Romanov flock with natural scrapie, J. Gen. Virol. (2000) 81:31153126.

[3] Arnold M.E., Ryan J.B., Konold T., Simmons M.M., Spencer Y.I., Wear A., et al., Estimating the temporal relationship between PrPSc detection and incubation period in experimental bovine spongiform encephalopathy of cattle, J. Gen. Virol. (2007) 88:31983208 .

[4] Atarashi R., Moore R.A., Sim V.L., Hughson A.G., Dorward D.W., Onwubiko H.A., et al., Ultrasensitive 
detection of scrapie prion protein using seeded conversion of recombinant prion protein, Nat. Methods. (2007) 4:645-650.

[5] Beekes M., Otto M., Wiltfang J., Bahn E., Poser S., Baier M., Late increase of serum S100 beta protein levels in hamsters after oral or intraperitoneal infection with scrapie, J. Infect. Dis. (1999) 180:518-520.

[6] Bendheim P.E., Bolton D.C., A 54-kDa normal cellular protein may be the precursor of the scrapie agent protease-resistant protein, Proc. Natl. Acad. Sci. USA (1986) 83:2214-2218.

[7] Benestad S.L., Sarradin P., Thu B., Schonheit J., Tranulis M.A., Bratberg B., Cases of scrapie with unusual features in Norway and designation of a new type, Nor98, Vet. Rec. (2003) 153:202-208.

[8] Brown P., Blood infectivity, processing and screening tests in transmissible spongiform encephalopathy, Vox Sang. (2005) 89:63-70.

[9] Brown P., Cervenakova L., Diringer H., Blood infectivity and the prospects for a diagnostic screening test in Creutzfeldt-Jakob disease, J. Lab. Clin. Med. (2001) 137:5-13.

[10] Brown P., Will R.G., Bradley R., Asher D.M., Detwiler L., Bovine spongiform encephalopathy and variant Creutzfeldt-Jakob disease: background, evolution, and current concerns, Emerging Infect. Dis. (2001) 7:6-16.

[11] Bruce M.E., Will R.G., Ironside J.W., McConnell I., Drummond D., Suttie A., et al., Transmissions to mice indicate that "new variant" CJD is caused by the BSE agent, Nature (1997) 389:498-501.

[12] Calavas D., Ducrot C., Baron T., Morignat E., Vinard J.L., Biacabe A.G., et al., Prevalence of BSE in western France by screening cattle at risk: preliminary results of a pilot study, Vet. Rec. (2001) 149:55-56.

[13] Carmona P., Monleon E., Monzon M., Badiola J.J., Monreal J., Raman analysis of prion protein in blood cell membranes from naturally affected scrapie sheep, Chem. Biol. (2004) 11:759-764.

[14] Castilla J., Saa P., Hetz C., Soto C., In vitro generation of infectious scrapie prions, Cell (2005) 121:195-206.

[15] Castilla J., Saa P., Soto C., Detection of prions in blood, Nat. Med. (2005) 11:982-985.

[16] Chang B., Cheng X., Yin S., Pan T., Zhang H., Wong P., et al., Test for detection of diseaseassociated prion aggregate in the blood of infected but asymptomatic animals, Clin. Vaccine Immunol. (2007) 14:36-43.

[17] Curin S., V, Bresjanac M., Popovic M., Pretnar H.K., Galvani V., Rupreht R., et al., Monoclonal antibody against a peptide of human prion protein discriminates between Creutzfeldt-Jacob's diseaseaffected and normal brain tissue, J. Biol. Chem. (2004) 279:3694-3698.

[18] Deleault N.R., Harris B.T., Rees J.R., Supattapone S., From the cover: formation of native prions from minimal components in vitro, Proc. Natl. Acad. Sci. USA (2007) 104:9741-9746.
[19] Deleault N.R., Lucassen R.W., Supattapone S., RNA molecules stimulate prion protein conversion, Nature (2003) 425:717-720.

[20] Deslys J.P., Comoy E., Hawkins S., Simon S., Schimmel H., Wells G., et al., Screening slaughtered cattle for BSE, Nature (2001) 409:476-478.

[21] Eloit M., Adjou K., Coulpier M., Fontaine J.J., Hamel R., Lilin T., et al., BSE agent signatures in a goat, Vet. Rec. (2005) 156:523-524.

[22] Everest D.J., Waterhouse S., Kelly T., Velo-Rego E., Sauer M.J., Effectiveness of capillary electrophoresis fluoroimmunoassay of blood PrpSc for evaluation of scrapie pathogenesis in sheep, J. Vet. Diagn. Invest. (2007) 19:552-557.

[23] Fraser H., The pathology of a natural and experimental scrapie, Front. Biol. (1976) 44:267-305.

[24] Gavier-Widen D., Stack M.J., Baron T., Balachandran A., Simmons M., Diagnosis of transmissible spongiform encephalopathies in animals: a review, J. Vet. Diagn. Invest. (2005) 17:509-527.

[25] Glock B., Winter M., Rennhofer S.O., Brunholzl E., Troscher D., Reisacher R.B., Mayr W.R., Transcript level of erythroid differentiation-related factor, a candidate surrogate marker for transmissible spongiform encephalopathy diseases in blood, shows a broad range of variation in healthy individuals, Transfusion (2003) 43:1706-1710.

[26] Grassi J., Comoy E., Simon S., Creminon C., Frobert Y., Trapmann S., et al., Rapid test for the preclinical postmortem diagnosis of BSE in central nervous system tissue, Vet. Rec. (2001) 149:577-582. [27] Grassi J., Creminon C., Frobert Y., Fretier P., Turbica I., Rezaei H., et al., Specific determination of the proteinase K-resistant form of the prion protein using two-site immunometric assays. Application to the post-mortem diagnosis of BSE, Arch. Virol. Suppl. (2000) 16:197-205.

[28] Green A.J., Cerebrospinal fluid brain-derived proteins in the diagnosis of Alzheimer's disease and Creutzfeldt-Jakob disease, Neuropathol. Appl. Neurobiol. (2002) 28:427-440.

[29] Green A.J., Jackman R., Marshall T.A., Thompson E.J., Increased S-100b in the cerebrospinal fluid of some cattle with bovine spongiform encephalopathy, Vet. Rec. (1999) 145:107-109.

[30] Grosset A., Moskowitz K., Nelsen C., Pan T., Davidson E., Orser C.S., Rapid presymptomatic detection of PrPSc via conformationally responsive palindromic PrP peptides, Peptides (2005) 26:2193-2200.

[31] Hibler C.P., Wilson K.L., Spraker T.R., Miller M.W., Zink R.R., DeBuse L.L., et al., Field validation and assessment of an enzyme-linked immunosorbent assay for detecting chronic wasting disease in mule deer (Odocoileus hemionus), white-tailed deer (Odocoileus virginianus), and Rocky Mountain elk (Cervus elaphus nelsoni), J. Vet. Diagn. Invest. (2003) 15:311-319.

[32] Hilton D.A., Ghani A.C., Conyers L., Edwards P., McCardle L., Penney M., et al., Accumulation of prion protein in tonsil and appendix: review of tissue samples, BMJ (2002) 325:633-634. 
[33] Hilton D.A., Ghani A.C., Conyers L., Edwards P., McCardle L., Ritchie D., et al., Prevalence of lymphoreticular prion protein accumulation in UK tissue samples, J. Pathol. (2004) 203:733-739.

[34] Jackman R., Everest D.J., Schmerr M.J., Khawaja M., Keep P., Docherty J., Evaluation of a preclinical blood test for scrapie in sheep using immunocapillary electrophoresis, J. AOAC Int. (2006) 89:720-727.

[35] Jackman R., Schmerr M.J., Analysis of the performance of antibody capture methods using fluorescent peptides with capillary zone electrophoresis with laserinduced fluorescence, Electrophoresis (2003) 24:892896.

[36] Jones M., Peden A., Prowse C., Groner A., Manson J., Turner M., et al., In vitro amplification and detection of variant Creutzfeldt-Jakob disease $\operatorname{PrP}(\mathrm{Sc})$, J. Pathol. (2007) 213:21-26.

[37] Korth C., Stierli B., Streit P., Moser M., Schaller O., Fischer R., et al., Prion (PrPSc)-specific epitope defined by a monoclonal antibody, Nature (1997) 390:74-77.

[38] Kurt T.D., Perrott M.R., Wilusz C.J., Wilusz J., Supattapone S., Telling G.C., et al., Efficient in vitro amplification of chronic wasting disease PrPres, J. Virol. (2007) 81:9605-9608.

[39] Lasch P., Beekes M., Schmitt J., Naumann D., Detection of preclinical scrapie from serum by infrared spectroscopy and chemometrics, Anal. Bioanal. Chem. (2007) 387:1791-1800.

[40] Lasch P., Schmitt J., Beekes M., Udelhoven T., Eiden M., Fabian H., et al., Antemortem identification of bovine spongiform encephalopathy from serum using infrared spectroscopy, Anal. Chem. (2003) 75:6673-6678.

[41] Llewelyn C.A., Hewitt P.E., Knight R.S., Amar K., Cousens S., Mackenzie J., Will R.G., Possible transmission of variant Creutzfeldt-Jakob disease by blood transfusion, Lancet (2004) 363:417-421.

[42] Lourenco P.C., Schmerr M.J., MacGregor I., Will R.G., Ironside J.W., Head M.W., Application of an immunocapillary electrophoresis assay to the detection of abnormal prion protein in brain, spleen and blood specimens from patients with variant Creutzfeldt-Jakob disease, J. Gen. Virol. (2006) 87:3119-3124.

[43] Miele G., Manson J., Clinton M., A novel erythroid-specific marker of transmissible spongiform encephalopathies, Nat. Med. (2001) 7:361-364.

[44] Missler U., Wiesmann M., Wittmann G., Magerkurth O., Hagenstrom H., Measurement of glial fibrillary acidic protein in human blood: analytical method and preliminary clinical results, Clin. Chem. (1999) 45:138-141.

[45] Moussa A., Coleman A.W., Bencsik A., Leclere E., Perret F., Martin A., Perron H., Use of streptomycin for precipitation and detection of proteinase $\mathrm{K}$ resistant prion protein (PrPsc) in biological samples, Chem. Commun. (Camb.) (2006) 9:973-975.

[46] Moynagh J., Schimmel H., Tests for BSE evaluated. Bovine spongiform encephalopathy, Nature (1999) 400:105.
[47] Murayama Y., Yoshioka M., Horii H., Takata M., Yokoyama T., Sudo T., et al., Protein misfolding cyclic amplification as a rapid test for assessment of prion inactivation, Biochem. Biophys. Res. Commun. (2006) 348:758-762.

[48] Nazor K.E., Kuhn F., Seward T., Green M., Zwald D., Purro M., et al., Immunodetection of diseaseassociated mutant PrP, which accelerates disease in GSS transgenic mice, EMBO J. (2005) 24:2472-2480. [49] Oesch B., Doherr M., Heim D., Fischer K., Egli S., Bolliger S., et al., Application of prionics Western blotting procedure to screen for BSE in cattle regularly slaughtered at Swiss abattoirs, Arch. Virol. Suppl. (2000) 16:189-195.

[50] Otto M., Wiltfang J., Differential diagnosis of neurodegenerative diseases with special emphasis on Creutzfeldt-Jakob disease, Restor. Neurol. Neurosci. (2003) 21:191-209.

[51] Otto M., Wiltfang J., Cepek L., Neumann M., Mollenhauer B., Steinacker P., et al., Tau protein and 14-3-3 protein in the differential diagnosis of Creutzfeldt-Jakob disease, Neurology (2002) 58:192197.

[52] Pan T., Chang B., Wong P., Li C., Li R., Kang S.C., et al., An aggregation-specific enzyme-linked immunosorbent assay: detection of conformational differences between recombinant PrP protein dimers and PrP(Sc) aggregates, J. Virol. (2005) 79:12355-12364.

[53] Pan T., Sethi J., Nelsen C., Rudolph A., Cervenakova L., Brown P., Orser C.S., Detection of misfolded prion protein in blood with conformationally sensitive peptides, Transfusion (2007) 47:14181425.

[54] Paramithiotis E., Pinard M., Lawton T., LaBoissiere S., Leathers V.L., Zou W.Q., et al., A prion protein epitope selective for the pathologically misfolded conformation, Nat. Med. (2003) 9:893-899. [55] Parveen I., Moorby J., Allison G., Jackman R., The use of non-prion biomarkers for the diagnosis of transmissible spongiform encephalopathies in the live animal, Vet. Res. (2005) 36:665-683.

[56] Peden A.H., Head M.W., Ritchie D.L., Bell J.E., Ironside J.W., Preclinical vCJD after blood transfusion in a PRNP codon 129 heterozygous patient, Lancet (2004) 364:527-529.

[57] Prusiner S.B., Prions, Proc. Natl. Acad. Sci. USA (1998) 95:13363-13383.

[58] Prusiner S.B., Scott M.R., DeArmond S.J., Cohen F.E., Prion protein biology, Cell (1998) 93:337-348.

[59] Ruth L., The quest for new prion tests, Anal. Chem. (2003) 75:32A-36A.

[60] Saa P., Castilla J., Soto C., Presymptomatic detection of prions in blood, Science (2006) 313:92-94.

[61] Saa P., Castilla J., Soto C., Ultra-efficient replication of infectious prions by automated protein misfolding cyclic amplification, J. Biol. Chem. (2006) 281:35245-35252.

[62] Saborio G.P., Permanne B., Soto C., Sensitive detection of pathological prion protein by cyclic amplification of protein misfolding, Nature (2001) 411:810813. 
[63] Safar J., Wille H., Itri V., Groth D., Serban H., Torchia M., et al., Eight prion strains have $\operatorname{PrP}(\mathrm{Sc})$ molecules with different conformations, Nat. Med. (1998) 4:1157-1165.

[64] Safar J.G., Scott M., Monaghan J., Deering C., Didorenko S., Vergara J., et al., Measuring prions causing bovine spongiform encephalopathy or chronic wasting disease by immunoassays and transgenic mice, Nat. Biotechnol. (2002) 20:1147-1150.

[65] Schaller O., Fatzer R., Stack M., Clark J., Cooley W., Biffiger K., et al., Validation of a western immunoblotting procedure for bovine $\operatorname{PrP}(\mathrm{Sc})$ detection and its use as a rapid surveillance method for the diagnosis of bovine spongiform encephalopathy (BSE), Acta Neuropathol. (1999) 98:437-443.

[66] Schmerr M.J., Cutlip R.C., Jenny A., Capillary isoelectric focusing of the scrapie prion protein, J. Chromatogr. A (1998) 802:135-141.

[67] Schmerr M.J., Goodwin K.R., Cutlip R.C., Jenny A.L., Improvements in a competition assay to detect scrapie prion protein by capillary electrophoresis, J. Chromatogr. B, Biomed. Appl. (1996) 681:29-35.

[68] Schmerr M.J., Jenny A.L., Bulgin M.S., Miller J.M., Hamir A.N., Cutlip R.C., Goodwin K.R., Use of capillary electrophoresis and fluorescent labeled peptides to detect the abnormal prion protein in the blood of animals that are infected with a transmissible spongiform encephalopathy, J. Chromatogr. A (1999) 853:207-214.

[69] Schmitt J., Beekes M., Brauer A., Udelhoven T., Lasch P., Naumann D., Identification of scrapie infection from blood serum by Fourier transform infrared spectroscopy, Anal. Chem. (2002) 74:3865-3868.

[70] Schutz E., Urnovitz H.B., Iakoubov L., SchulzSchaeffer W., Wemheuer W., Brenig B., Bov-tA short interspersed nucleotide element sequences in circulating nucleic acids from sera of cattle with bovine spongiform encephalopathy (BSE) and sera of cattle exposed to BSE, Clin. Diagn. Lab Immunol. (2005) 12:814-820.

[71] Simmons M.M, Spiropoulos J., Hawkins S.A.C., Bellworthy S.J., Tongue S.C., Approaches to investigating transmission of spongiform encephalopathies in domestic animals using BSE as an exemple, Vet. Res. (2008) 39:34.

[72] Soto C., Anderes L., Suardi S., Cardone F., Castilla J., Frossard M.J., et al., Pre-symptomatic detection of prions by cyclic amplification of protein misfolding, FEBS Lett. (2005) 579:638-642.

[73] Spraker T.R., O’Rourke K.I., Balachandran A., Zink R.R., Cummings B.A., Miller M.W., Powers B.E., Validation of monoclonal antibody F99/97.6.1 for immunohistochemical staining of brain and tonsil in mule deer (Odocoileus hemionus) with chronic wasting disease, J. Vet. Diagn. Invest. (2002) 14:3-7.

[74] Stack M., Jeffrey M., Gubbins S., Grimmer S., Gonzalez L., Martin S., et al., Monitoring for bovine spongiform encephalopathy in sheep in Great Britain, 1998-2004, J. Gen. Virol. (2006) 87:2099-2107.

[75] Stack M., Jeffrey M., Gubbins S., Grimmer S., Gonzalez L., Martin S., et al., Monitoring for bovine spongiform encephalopathy in sheep in Great Britain, 1998-2004, J. Gen. Virol. (2006) 87:2099-2107.

[76] Stack M.J., Chaplin M.J., Clark J., Differentiation of prion protein glycoforms from naturally occurring sheep scrapie, sheep-passaged scrapie strains (CH1641 and SSBP1), bovine spongiform encephalopathy (BSE) cases and Romney and Cheviot breed sheep experimentally inoculated with BSE using two monoclonal antibodies, Acta Neuropathol. (2002) 104:279286.

[77] Thomzig A., Spassov S., Friedrich M., Naumann D., Beekes M., Discriminating scrapie and bovine spongiform encephalopathy isolates by infrared spectroscopy of pathological prion protein, J. Biol. Chem. (2004) 279:33847-33854.

[78] Tyler J.W., Lakritz J., Weaver D., Johnson G., VanMetre D., Smith K., et al., The 14-3-3 cerebrospinal fluid immunoassay lacks utility in the diagnosis of clinical scrapie, J. Vet. Diagn. Invest. (2001) 13:537-539.

[79] van Keulen L.J., Schreuder B.E., Meloen R.H., Mooij-Harkes G., Vromans M.E., Langeveld J.P., Immunohistochemical detection of prion protein in lymphoid tissues of sheep with natural scrapie, J. Clin. Microbiol. (1996) 34:1228-1231.

[80] van Keulen L.J., Schreuder B.E., Meloen R.H., Poelen-van den B.M., Mooij-Harkes G., Vromans M.E., Langeveld J.P., Immunohistochemical detection and localization of prion protein in brain tissue of sheep with natural scrapie, Vet. Pathol. (1995) 32:299308.

[81] Wadsworth J.D., Joiner S., Hill A.F., Campbell T.A., Desbruslais M., Luthert P.J., Collinge J., Tissue distribution of protease resistant prion protein in variant Creutzfeldt-Jakob disease using a highly sensitive immunoblotting assay, Lancet (2001) 358:171-180.

[82] Weber P., Giese A., Piening N., Mitteregger G., Thomzig A., Beekes M., Kretzschmar H.A., Generation of genuine prion infectivity by serial PMCA, Vet. Microbiol. (2007) 123:346-357.

[83] Wells G.A., Wilesmith J.W., The neuropathology and epidemiology of bovine spongiform encephalopathy, Brain Pathol. (1995) 5:91-103.

[84] Wroe S.J., Pal S., Siddique D., Hyare H., Macfarlane R., Joiner S., et al., Clinical presentation and pre-mortem diagnosis of variant Creutzfeldt-Jakob disease associated with blood transfusion: a case report, Lancet (2006) 368:2061-2067.

[85] Xiang W., Windl O., Wunsch G., Dugas M., Kohlmann A., Dierkes N., et al., Identification of differentially expressed genes in scrapie-infected mouse brains by using global gene expression technology, J. Virol. (2004) 78:11051-11060.

[86] Yang W.C., Schmerr M.J., Jackman R., Bodemer W., Yeung E.S., Capillary electrophoresis-based noncompetitive immunoassay for the prion protein using fluorescein-labeled protein A as a fluorescent probe, Anal. Chem. (2005) 77:4489-4494.

[87] Zou W.Q., Zheng J., Gray D.M., Gambetti P., Chen S.G., Antibody to DNA detects scrapie but not normal prion protein, Proc. Natl. Acad. Sci. USA (2004) 101:1380-1385. 